\section{The Management of Terminal Malignant Disease}

Dame Cicely Saunders, 250 pages, London, £22.50, Edward Arnold, 1984

Presentation of the material of this edition is essentially the same as previously, with up-dated references and statistics, but it has been rearranged to make study easier. The major additions to the clinical content are in line with current emphasis on home care and there is some interesting new material on paediatric terminal care. In particular, Dr Twycross's chapter on pain relief has been much improved. There is a new chapter by Robert Baxter which deals with specialised techniques for pain control. Mary Baine's chapter on the control of other symptoms has been extensively rewritten and is much clearer. It was a delight to read Professor Dunstan's chapter on discerning the duties and of particular importance are his comments on the duties of the doctor and nurse, although I think it would have been fascinating had he expanded his short discursion on the duties of the patient. His comment that the patient is in no condition to be lectured on ethics implies a number of value judgements, for instance, that the rightness of actions changes with physical state. His comments on the patient's right to die, I am sure, will provoke much thought.

In summary, this revised edition will prove an even more valuable vademecum for those working in the field of terminal care. As the general editor says in the foreword, there is some controversial material and it is well known that the area of terminal care receives much stimulus from the strength of the personalities involved. However, the statement 'it is extremely important to treat restlessness actively because of the stress it causes family and staff, if not the patient himself is a very difficult one to understand and I think highlights how ethical considerations may help to clarify what has often been obscured by emotion.

DR ROBIN PUGSLEY Medical Director, St foseph's Home Care Service, St Joseph's Hospice, Mare Street, Hackney, London E8 4SA

\section{In Vitro Fertilisation and Embryo Transfer}

Editors, Alan Trounson and Carl Wood, 254 pages, Great Britain, £25, Churchill Livingstone, 1984

In vitro fertilisation is a subject which interests not only health-care professionals directly involved with the alleviation of subfertility, but many others also because of the moral and legal implications of establishing the precursors of human life in the laboratory.

This book, edited by two pioneers in the field of in vitro fertilisation, Professor Carl Wood and Dr Alan Trounson of the Monash group in Australia, is comprised of fifteen chapters written by internationally acknowledged experts. It is divided into three parts and covers most aspects of this highly specialised subject. Part one is concerned with basic physiology of in vitro fertilisation and draws heavily on animal models to demonstrate the principles involved. Part two, Human Physiology, specifically deals with aspects of ovulation induction, the fertilisation process, the assessment of pre-embryo viability, the ultrastructure of pre-embryos and aspects of their long-term preservation at low temperatures. Highly recommended are the chapters on the endocrinology of follicular growth (Healy and Hodgen) and stimulation of ovulation (Kerin and Seamark) which are the most lucid that I have read on these somewhat involved topics. They will be of particular help to the non-clinician trying to fathom the empirical nature of many of the stimulation regimes currently being applied to in vitro fertilisation to try and attain or improve clinical success. Part three is the How to do it section of the book, and covers patient selection, techniques for oocyte recovery, embryo replacement and the management of ensuing pregnancies.

Of interest to the ethicist are the opening and closing chapters. John Biggers's excellent introduction puts into historical perspective the attempts to alleviate tubal infertility, and the history of in vitro fertilisation and embryo transfer. It will come as a surprise to many, that the first embryo transfer occurred as early as 1890 , and the first attempts at in vitro fertilisation in the 1930 s. It is also not commonly acknowledged that the first human pregnancy following in vitro fertilisation and embryo replacement occurred in 1975 although it was not until 1978 that the first live birth was reported. Professor Biggers's chapter re-emphasises the inappropriateness of the current political hysteria about research which utilises fertilisation in vitro when controls have been called for by involved scientists and clinicians for well over a decade.

The final chapter by the doyen of the subject, Bob Edwards, provides a perspective of a different kind. It is a realistic appraisal of some of the scientific and medical advances that have accrued as a result of the clinical practice of the discipline, and those that could, and should accrue if research in the field is not prematurely and unnecessarily halted. For those unfamiliar with the possibilities for the future, this chapter will be revealing; for those inherently against the idea of using human pre-embryos for research, this chapter will probably merely reinforce their prejudices. For both however, there is much to deliberate on.

Thus, rather than a treatise on the moral or ethical debates about in vitro fertilisation, the bulk of the book is devoted to the biological bases of, and the therapeutic use of in vitro fertilisation and embryo replacement. Being a book written in 1982/83 much of the data about the therapeutic results of in vitro fertilisation are now obsolete.

This is not a failing of the authors or the editors, but a function of the inherent obsolescence of books about rapidly changing fields. However, this should in no way detract from its merit, for as it stands it is probably the best book on the subject currently available although, with the explosion of knowledge in this field, is unlikely to remain so for long.

PETER BRAUDE Senior Research Associate, Department of Obstetrics and Gynaecology, University of Cambridge Clinical School

\section{Selective \\ Nontreatment of Handicapped Newborns}

Robert Weir, 292 pages, New York, $£ 25.00$, Oxford University Press, 1984

This is an uncomfortable book for a paediatrician to review. By exploring the areas of ethical dilemma for the practising doctor involved in the care of the newborn, many questions which conveniently (or perhaps deliberately) have remained dormant, are thrust into life. The arrangement of the material, with its case histories and personal views, brings the reader into a decisionmaking role. These decisions, as reported in the book, can then be compared with those of the experts, allowing the reader a very active - though exhausting - experience of the difficulties.

The book starts with a review of the history of infanticide which, although morbidly fascinating, perhaps suggests to the reader that the author has come to 